This is the peer reviewed version of the following article: O'Carroll, R. E., Haddow, L., Foley, L. and Quigley, J. (2017), If you needed an organ transplant would you have one? The effect of reciprocity priming and mode of delivery on organ donor registration intentions and behaviour. Br J Health Psychol, 22:

577-588, which has been published in final form at

https://doi.org/10.1111/bjhp.12248. This article may be used for noncommercial purposes in accordance With Wiley Terms and Conditions for selfarchiving. 


\section{British Journal of Health Psychology \\ If you needed an organ transplant would you have one? The effect of reciprocity priming and mode of delivery on organ donor registration intentions and behaviour --Manuscript Draft--}

\begin{tabular}{|c|c|}
\hline Article Type: & Article \\
\hline Full Title: & $\begin{array}{l}\text { If you needed an organ transplant would you have one? The effect of reciprocity } \\
\text { priming and mode of delivery on organ donor registration intentions and behaviour }\end{array}$ \\
\hline Corresponding Author: & $\begin{array}{l}\text { Ronan E. O'Carroll, Ph.D. } \\
\text { University of Stirling } \\
\text { Stirling, UNITED KINGDOM }\end{array}$ \\
\hline Corresponding Author E-Mail: & reo1@stir.ac.uk \\
\hline \multirow[t]{2}{*}{ Order of Authors (with Contributor Roles): } & $\begin{array}{l}\text { Ronan E. O'Carroll, Ph.D. (Conceptualization; Funding acquisition; Methodology; } \\
\text { Supervision; Writing - original draft; Writing - review \& editing) }\end{array}$ \\
\hline & Lorna Haddow (Investigation; Methodology; Project administration) \\
\hline \multicolumn{2}{|l|}{ Funding Information: } \\
\hline Keywords: & organ donation; reciprocity; donor; altruism; reciprocity. \\
\hline Manuscript Classifications: & $\begin{array}{l}\text { Experimental; Randomised controlled trials; Health-related behaviours; Psychological } \\
\text { interventions }\end{array}$ \\
\hline Abstract: & $\begin{array}{l}\text { Objective: There are approximately } 6,500 \text { people on the UK national transplant waiting } \\
\text { list, around } 400 \text { of whom die every year. Only } 35 \% \text { of the UK population are currently } \\
\text { on the organ donation register. We report } 2 \text { studies examining whether a reciprocity } \\
\text { prime, in which participants were asked whether they would accept a donated organ, } \\
\text { increased organ donation intentions and behaviour. Design: Between participants, } \\
\text { randomized-controlled design. Methods: In } 2 \text { studies, participants who were not } \\
\text { currently registered organ donors took part either face-to-face or online, and were } \\
\text { randomly allocated to a reciprocity prime or control condition. Following the } \\
\text { manipulation they were asked to indicate, on either a paper or online questionnaire, } \\
\text { their intention to join the organ donor register. Study } 2 \text { was similar to Study } 1 \text { but with } \\
\text { the addition that after reporting intention, participants were then offered an organ } \\
\text { donation information leaflet or the opportunity to click a link for further information } \\
\text { (proxy behavioural measure). Results: In both studies, reciprocity primed participants } \\
\text { reported greater intentions to register than controls. However, in Study } 2 \text {, no effect on } \\
\text { donation behaviour was found. Conclusions: Reciprocal altruism may be a useful tool } \\
\text { in increasing intentions to join the organ donor register. Further evaluation is required } \\
\text { to determine whether this increase in intention can be translated into organ donation } \\
\text { behaviour. }\end{array}$ \\
\hline \multicolumn{2}{|l|}{ Additional Information: } \\
\hline Question & Response \\
\hline $\begin{array}{l}\text { If you have any potentially competing } \\
\text { interests to declare, please enter them in } \\
\text { the box below. If you have no interests to } \\
\text { declare, please enter 'none'. Please } \\
\text { declare any financial relationships (such } \\
\text { as employment, consultancies, stock } \\
\text { ownership or options, honoraria, patents, } \\
\text { paid expert testimony) or any personal } \\
\text { relationships which could be perceived to } \\
\text { undermine the credibility of your research. }\end{array}$ & None \\
\hline
\end{tabular}


By conflict of interest, we are referring to cases where professional judgment in relation to the research, or the welfare of research participants, may be influenced by another interest, such as financial gain or personal relationships.

Does this submission have any links or overlap with any other submitted or published manuscripts, for this or any other publication? (For example; as part of a long-term project, using a shared data set, a response to, or extension of, earlier work.) If yes, please give brief details. If no, please enter 'none'.

Any overlap not declared and later discovered will result in the manuscript being withdrawn from consideration.

Please specify the word count of your

manuscript (excluding the abstract, tables, figures and references).

Do you use Twitter for academic

purposes? (If you do and your paper is accepted, we will 'mention' you when we share a link to the online article.) 
Running head: Reciprocity priming and organ donation

\title{
If you needed an organ transplant would you have one? The effect of reciprocity priming and mode of delivery on organ donor registration intentions and behaviour
}

\author{
Ronan E. O'Carroll ${ }^{1}$, Lorna Haddow ${ }^{1}$, Laura Foley ${ }^{1}$ and Jody \\ Quigley $^{1}$
}

${ }^{1}$ Division of Psychology, School of Natural Sciences, University of Stirling, Stirling FK9 4LA, UK

Word count (exc. figures/tables): 3,794

*Requests for reprints should be addressed to Professor Ronan E. O'Carroll, Division of Psychology, School of Natural Sciences, University of Stirling, Stirling FK9 4LA, UK (e-mail: reo1@stir.ac.uk

Accepted for publication in British Journal of Health Psychology published by Wiley 
Running head: Reciprocity priming and organ donation

\title{
If you needed an organ transplant would you have one? - Reciprocity priming and organ donation
}

\author{
Ronan E. O’Carroll ${ }^{1}$, Lorna Haddow ${ }^{1}$, Laura Foley ${ }^{1}$ and Jody \\ Quigley $^{1}$
}

${ }^{1}$ Division of Psychology, School of Natural Sciences, University of Stirling, Stirling FK9 4LA, UK

Word count (exc. figures/tables): 3,219

*Requests for reprints should be addressed to Professor Ronan E. O’Carroll, Division of Psychology, School of Natural Sciences, University of Stirling, Stirling FK9 4LA, UK (e-mail: reo1@stir.ac.uk). 


\section{$\underline{\text { Additional information requested }}$}

\section{Contributor roles}

Ronan E. O’Carroll: Conceptualization; Funding acquisition; Methodology; Project administration; Supervision; Writing - review \& editing.

Lorna Haddow: Investigation; Methodology; Project administration. (NB. Study 2 is based on work carried out by Lorna Haddow in her capacity as a Carnegie summer student).

Laura Foley: Investigation; Methodology; Project administration. (NB. Study 1 is based on work carried out by Laura Foley for her MSc dissertation).

Jody Quigley: Data curation; Formal analysis; Writing - original draft; Writing - review \& editing.

\section{Conflict of interest statement}

None. 


\section{Statement of contribution}

What was already known? Demand for organs in the UK far outstrips supply, so finding strategies to increase registration on the organ donor register could save hundreds of lives per year. Despite the majority of people in the UK agreeing that organ donation is a good thing, most people do not register as donors. A limited amount of evidence of the impact of perceived reciprocity suggests that encouraging people to consider themselves as recipients and priming ideas of shared responsibility may increase the likelihood of their subsequent willingness to register.

\section{What does this study add?}

- Novel evidence that employing a simple reciprocity prime increases organ donor registration intentions.

- Replication of findings across two separate studies.

- Novel examination of the impact of mode of delivery of messages to encourage organ donation.

- A basis for further research into the translation of intentions into organ donor registration behaviour. 
If you needed an organ transplant would you have one? The effect of reciprocity priming and mode of delivery on organ donor registration intentions and behaviour

Objective: There are approximately 6,500 people on the UK national transplant waiting list, around 400 of whom die every year. Only $35 \%$ of the UK population are currently on the organ donation register. We report 2 studies examining whether a reciprocity prime, in which participants were asked whether they would accept a donated organ, increased organ donation intentions and behaviour. Design: Between participants, randomized-controlled design. Methods: In 2 studies, participants who were not currently registered organ donors took part either face-to-face or online, and were randomly allocated to a reciprocity prime or control condition. Following the manipulation they were asked to indicate, on either a paper or online questionnaire, their intention to join the organ donor register. Study 2 was similar to Study 1 but with the addition that after reporting intention, participants were then offered an organ donation information leaflet or the opportunity to click a link for further information (proxy behavioural measure). Results: In both studies, reciprocity primed participants reported greater intentions to register than controls. However, in Study 2, no effect on donation behaviour was found. Conclusions: Reciprocal altruism may be a useful tool in increasing intentions to join the organ donor register. Further evaluation is required to determine whether this increase in intention can be translated into organ donation behaviour. 
Around 6,500 people in the UK are in need of an organ transplant at any given time, but with only $35 \%$ of the UK population registered to donate their organs, approximately 400 people die each year whilst waiting for an organ (NHSBT, 2016a). This is despite the UK population holding generally positive views about organ donation, with $86 \%$ of individuals supporting it, and 51\% strongly supporting it (NHSBT, 2013). The development of effective strategies to translate these positive views into action is imperative to increasing the number of registered donors and saving lives.

\section{Motivations for organ donation}

Altruism, described by Trivers (1971) as "behaviour that benefits another organism while being apparently detrimental to the organism performing the behaviour, benefit and detriment being defined in terms of contribution to inclusive fitness" (p35). Altruism has traditionally been considered intrinsic for both blood and organ donor registration, in that the actions of the donor are intended to benefit the recipient without necessary reward or benefit to the donor (Nuffield Council on Bioethics, 2011; Department of Health, 2000; Elster, 1990). However, the desires to aid medical science and to be useful after death have been cited as the most common reasons for organ donor registration (Bolt, Venbrux, Eisinga, Kuks, Veening \& Gerrits, 2010; Cornwall, Perry, Louw \& Stringer, 2012), and some scholars argue that a behaviour is not genuinely altruistic if it is driven by the agent's desire (Nagel, 1970). Furthermore, perceived moral norms appear to play a significant role in organ donation decisions (Delaney \& White, 2015), so social expectations and perceived moral obligations may play a role (Schwartz, 1977). However, given the low rates of registration to become an organ donor, altruism and norms alone are clearly not sufficient to ensure that supply meets demand. It has been proposed that the underlying mechanism motivating many people to donate organs may in fact not be altruistic, but rather the result of solidarity with, and the associated goal of benefiting, a particular in-group (e.g., family members, co-nationals) or 
“common project” (Saunders, 2012). As such, helping others may actually serve to also achieve personal goals, such that the benefits obtained are mutual.

\section{Reciprocal altruism}

Reciprocal altruism (RA), described by Silk (2013) as "a process that favours costly cooperation among reciprocating partners" (p. R827), has been observed across a number of species (Silk, 2013; Trivers, 1971). RA is vital for group cohesion and for ensuring survival of the group, and has thereby played an important role in human evolution. RA elicits a sense of joint moral obligation, in which each party is expected to make their own relative contribution for the advancement of the group, and deviation from expected norms results in disapproval, guilt or even punishment. RA has been proposed as a potentially effective mechanism through which organ donor registration might be increased (Landry, 2006).

Landry (2006) argued that altruism can be reinforced by reciprocity, and that in a system where altruists are reciprocally rewarded for their altruism - whilst those who violate altruistic norms are disadvantaged - altruism will thrive. Landry argued that in order to overcome the many barriers that prevent people from registering as organ donors, campaigns must appeal to individuals' self-interest, which must be balanced with their desire to do what is fair and just. For example, he suggested that the choice between donating one's organs ("altruism") and not donating one's organs ("selfishness") should include an additional third option, in which one can opt to donate one's organs to only those who have also agreed to donate theirs ("reciprocity"). This third option suggests to the decision-maker that there is a potential penalty for not behaving altruistically, such that should they choose not to donate their organs and later require an organ themselves, they would not receive one from those who engage only in reciprocal altruism, whilst had they agreed to donate, they would have had access to an extended pool of potential (reciprocal) donors. He tested these ideas in a pilot study with medical students. At baseline, 59\% were willing to donate their organs. When 
questioned about their willingness to accept an organ if they needed it to save their life, $100 \%$ stated that they would. When this was then immediately followed up with a question about their willingness to donate their organs, $74 \%$ now said they would, $20 \%$ said they would but only reciprocally, and only $2 \%$ refused. Prompting participants to consider their own potential future need for an organ, along with the suggestion that they might be disadvantaged if they refused to donate their own, substantially increased donation intentions. Landry argues that employing reciprocal altruism in this way could be an effective method through which organ donations might be increased. Nadel and Nadel (2005) agree with this view and further suggest that much like time spent on an organ waiting list contributes to who receives an organ, so too should time spent on a donor list, such that registering early on in life carries extra benefits.

The NHS Blood and Transplant campaign currently attempts to draw upon reciprocal altruism, asking "If you needed an organ transplant would you have one?" in its marketing materials (NHSBT, 2016b). The Cabinet Office's Behavioural Insights Team (in collaboration with NHS Blood and Transplant, the Government Digital Service, the Department of Health, and the Driving and Vehicle Licencing Agency) found that displaying these types of messages (specifically, "If you needed an organ transplant, would you have one? If so, please help others") on high traffic www.GOV.UK webpages encouraged people to register as organ donors. They estimate that an extra 96,000 registrations could be achieved per year using this type of reciprocity priming (BIT, 2013). It could be argued that prompting participants to adopt the perspective of the recipient may promote ideas of self-preservation, and increase levels of empathy towards those in need of organs. Additionally, the decision to donate one's organs may also be influenced by consideration of potential recipients' donor registration status (which of course would be unlikely to affect outcomes for the original donor). Stijnen and Dijker (2010) found that participants perceived organ donation to be more just when 
potential recipients were themselves registered donors. Recipients who were not registered donors themselves aroused feelings of injustice and anger, and donation to such recipients elicited less sympathy and less positive self-feelings than did donation to registered donor recipients. Contribution to a common pool of organs from which other contributors may benefit (at the exclusion of non-donors), may therefore be perceived by many as the fairest system.

\section{Mode of delivery}

In addition to the content of messages aiming to increase organ donor registration, the form of delivery may also have a significant impact on their effectiveness (Dombrowski, O’Carroll \& Williams, 2016). For example, interventions designed to alter behaviour have previously been shown to be more effective when delivered face-to-face compared to when delivered online (e.g., Wing, Tate, Gorin, Raynor \& Fava, 2006). This may be due to participants' desire to please the researcher/practitioner by engaging in the behaviour they believe is expected of them (e.g., Nichols \& Maner, 2008), or it may be something akin to the "therapist effect" observed in therapeutic settings, where mere interaction with a therapist is itself a source of variance (Wiborg, Knoop, Wensing \& Bleijenberg, 2012). However, other behavioural research suggests that face-to-face and online methods yield almost identical findings (e.g., Casler, Bickel \& Hackett, 2013), so it remains unclear what effect, if any, the mode through which research is conducted has on participants' behaviour.

\section{The current research}

This paper reports on two studies. Study 1 had two aims: i) to determine whether a reciprocity prime is effective in increasing organ donor registration intentions in those who are not currently registered; and ii) to determine whether any differences observed depend on the mode through which the study is conducted (face-to-face versus online). Study 2 had three aims: i) to determine whether a reciprocity prime is effective in increasing organ donor 
registration intentions; ii) to determine whether a reciprocity prime has any effect on a proxy behavioural measure of organ donor registration, i.e. taking an information leaflet or viewing a registration site; and iii) to examine whether the mode through which the study is conducted (face-to-face or online) makes any difference to stated organ donor registration intentions or on a proxy behavioural measure of organ donor behaviour.

\section{Study 1: Methods}

\section{Participants}

244 participants over the age of 18 were recruited (59.4\% female, modal age group 18-24 years), of whom $57.4 \%(\mathrm{~N}=140)$ were not currently registered organ donors. Of these, 83 took part in the face-to-face part of the study, and 57 in the online part. Demographic information for participants can be found in Table 1, whilst Table 2 provides a summary of participants in each condition, for each mode of delivery. Those who reported already having registered as organ donors took part in an alternate study (reported elsewhere). Those who were unsure whether or not they were registered organ donors were excluded from the study.

[Table 1 about here]

[Table 2 about here]

\section{Design}

A between participants, randomized-controlled design was used. Those not currently registered as organ donors were randomly assigned to either the reciprocity prime condition or a control condition to determine the effect of a reciprocity prime on reported intention to 
register as an organ donor. The same applied to both the face-to-face and online components of the study.

\section{Procedure}

For the face-to-face delivery mode, participants were recruited opportunistically, through approaching potential participants around the university campus and local workplaces. For online delivery, participants were recruited opportunistically through advertisements on social media. All participants were invited to read an information sheet and sign a consent form/click a consent box prior to participation. Consenting participants provided basic demographics. Those not currently registered as organ donors were randomly allocated (using an online randomiser - www.randomizer.org) to either the reciprocity prime or control condition. Prime condition participants completed a short questionnaire consisting of a priming question and two questions regarding intention to register as an organ donor (see "Measures" below). Control condition participants completed a similar questionnaire with a neutral "filler" question in place of the prime, and the same two questions regarding intention to register as an organ donor. Ethical approval for the study was obtained from the University of XXX Psychology Ethics Committee.

\section{Measures}

Reciprocity prime/ control. The reciprocity prime was based on marketing materials used by the UK NHS Blood and Transplant's organ donation campaign. Participants were required to respond on a seven-point likert scale from "Strongly disagree" to "Strongly agree", to the item "I would accept an organ from a deceased donor in order to save my own life". The control item was "Organ donation is important", and participants responded on the same seven-point scale.

Organ donation registration intention. All participants responded to the same two intention items: "I strongly intend to donate my organs in the future" and "I will definitely 
donate my organs when I die". Responses to both items were given on the same seven-point scale as above, and averaged to produce one overall organ donation registration intention score.

\section{Analyses}

Chi-squared analyses were used to determine whether there were any differences in demographic characteristics between prime condition participants and control participants. A two-way mixed ANOVA was run to compare differences in intention to donate, across experimental conditions and modes of delivery.

\section{Study 1: Results}

\section{Demographic characteristic comparisons}

No significant differences were found in age $\left(\chi^{2}(5)=3.78, \mathrm{p}=.581\right)$ or gender $\left(\chi^{2}(1)\right.$ $=1.49, \mathrm{p}=.222)$ between prime and control participants.

\section{Effect of reciprocity prime and mode of delivery on registration intentions}

The means and standard deviations for intention to donate organs in each condition are illustrated in Table 3.

[Table 3 about here]

A two-way mixed ANOVA was run to test for differences in intention to donate organs between those in the reciprocity prime condition and controls, and to test for any interaction between experimental condition and mode of delivery. A main effect was found for experimental group, with prime condition participants scoring significantly higher on intention than controls $\left(\mathrm{F}(1,136)=10.24, \mathrm{p}=.002\right.$, partial $\left.\mathrm{p}^{2}=.07\right)$, but no significant effect 
was found for mode of delivery $(\mathrm{F}(1,136)=1.31, \mathrm{p}=.255)$, and no interaction effect was observed $(\mathrm{F}(1,136)=.02, \mathrm{p}=.891)$.

\section{Study 2: Methods}

\section{Participants}

1,066 participants over the age of 18 were recruited in total $(55.2 \%$ female, modal age-group 45-54 years), $48.5 \%(\mathrm{~N}=518)$ of whom reported that they were not currently registered organ donors. For the face-to-face component of the study, 599 participants (336 non-donors) were recruited opportunistically from several Scottish town/city centres (Glasgow, Edinburgh, Stirling, Aberdeen and Perth). For the online component, 466 participants (182 non-donors) were recruited online via social media, email, the University online portal, and several local workplaces (a financial company, a hotel company, a computer technologies company, a further education college and a befriending charity). Participant demographics are illustrated in Table 4. Those who reported already having registered as organ donors took part in an alternate study (reported elsewhere). Those who were unsure whether or not they were registered organ donors $(\mathrm{N}=69)$ were treated as though they were not registered (i.e. they were allocated to either the prime or control condition). Table 5 provides a summary of participants in each condition, for each part of the study.

[Table 4 about here]

[Table5 about here]

\section{Design}


A similar between participants, randomized-controlled design was used, across two separate modes of delivery. In both modes, those not currently registered as organ donors were randomly assigned to either the reciprocity prime or control condition to determine the effect of a reciprocity prime on reported intention to register as an organ donor, and on the likelihood of either taking an organ donor information leaflet (face-to-face mode) or clicking on a link to the NHS organ donor registration site (online mode) (both proxy behavioural measures of organ donor registration).

\section{Procedure}

All participants were invited to read an information sheet and sign a consent form/click a consent box prior to participation. Consenting participants provided basic demographics, and those not currently registered as organ donors were randomly allocated (using www.randomizer.org/) to either the reciprocity prime or control condition. Across both modes of delivery, prime condition participants completed a short questionnaire consisting of a priming question and two questions regarding intention to register as an organ donor (see "Measures" below). Control condition participants completed only the two questions regarding intention to register as an organ donor (see below). Ethical approval for the study was obtained from the University of XXX Psychology Ethics Committee.

\section{Measures}

Reciprocity prime. For both modes of delivery, those in the reciprocity prime condition were required to respond to the item "I would accept an organ from a deceased donor in order to save my own life", on a seven-point likert scale from "Strongly disagree" to "Strongly agree".

Organ donation registration intention. Both reciprocity prime and control participants were then required to respond to the same two intention items: "I strongly intend to donate my organs when I die" and "I will definitely donate my organs when I die", on the 
same seven-point scale as above. Scores were averaged to produce one overall organ donation registration intention score.

Behavioural measure of organ donor registration. Following questionnaire completion, participants in the face-to-face component were offered a leaflet on organ donation. Whether or not they took one was recorded. Participants of the online component were asked "Would you like to see the link to the NHS website to register as an organ donor?". Whether they clicked "yes" or "no" was recorded.

\section{Analyses}

Chi-squared tests examined differences in demographic characteristics between prime condition participants and controls. A two-way mixed ANOVA was used to compare mean organ donation registration intentions between participants in the prime condition and in the control condition, and between face-to-face and online delivery. Chi-squared tests were used to determine whether there was a difference in taking an information leaflet (face-to-face), or in opting to see the link to the NHS organ donation registration website (online), between those in the prime condition and controls.

\section{Study 2: Results}

\section{Demographic characteristic comparisons}

Prime condition participants did not differ significantly from controls in age $\left(\chi^{2}(5)=\right.$ $8.13, \mathrm{p}=.149)$ or gender $\left(\chi^{2}(1)=0.62, \mathrm{p}=.430\right)$.

\section{Effect of reciprocity prime on registration intentions}

The means and standard deviations for intention to donate organs in each condition are illustrated in Table 6. 
A two-way mixed ANOVA found a significant main effect of experimental group on intention: those in the reciprocity prime group had higher intention scores than controls $(\mathrm{F}(1$, $507)=5.39, \mathrm{p}=.021$, partial $\left.\mathrm{y}^{2}=.01\right)$. No main effect on intention was found for mode of delivery $(\mathrm{F}(1,507)=3.34, \mathrm{p}=.068)$, but a significant interaction was found between experimental group and mode of delivery, $\left(\mathrm{F}(1,507)=5.32, \mathrm{p}=.021\right.$, partial $\left.\mathrm{y}^{2}=.01\right)$, with those in the prime group scoring higher on intention than controls when the prime was delivered online compared to face-to-face. ${ }^{1}$

Examination of individual means indicated that in the face-to-face delivery format, the scores for intention were identical in the prime and control conditions (4.90) but there appeared to be a difference between intention scores in the face-to-face control group and the online control group. A post-hoc independent samples t-test confirmed that intention scores were significantly higher in the face-to-face control group than in the online control group ( $\mathrm{t}$ $(269)=3.03, \mathrm{p}=.003)$, whilst no such differences existed between the face-to-face prime group and the online prime group $(\mathrm{t}(238)=0.33, \mathrm{p}=.745)$.

\section{Effect of reciprocity prime on leaflet collection/web-link viewing}

Overall, there was no difference in taking a leaflet/clicking the link between prime and control participants; $\chi^{2}(1)=1.33, \mathrm{p}=.249$. When broken down by delivery mode, controls in face-to-face mode were more likely to take an information leaflet than those in the prime condition; $\chi^{2}(1)=5.44, p=.020$. In online mode, there was no difference in clicking

\footnotetext{
${ }^{1}$ This analysis on intention was re-run, excluding those participants who were unsure of their donation status. With this reduced power, overall, prime participants still had higher means than controls (prime mean $=4.71$, $\mathrm{SD}=1.99$; control mean $=4.49, \mathrm{SD}=1.91)$ but the difference is now of borderline significance $(\mathrm{F}(1,440)=$ $3.10, \mathrm{p}=.079$, partial $\left.\mathrm{p}^{2}=.01\right)$. There is still no significant effect for mode of delivery $(\mathrm{F}(1,440)=1.40, \mathrm{p}=$ $.237)$, and there is still an interaction effect, with prime participants scoring higher than controls on intention in online mode $\left(\mathrm{F}(1,440)=16.38, \mathrm{p}=.037, \mathrm{\eta}^{2}=.01\right)$.
} 
on the organ donation link between prime and control participants; $\chi^{2}(1)=3.27, p=.071$.

Table 7 summarises the proportion of people taking leaflets/clicking links in each condition.

\section{[Table 7 about here]}

\section{Overall Discussion}

In Study 1 a reciprocity prime manipulation led to greater reported intentions to sign the organ donor register, regardless of whether this was done face-to-face or online. Similarly, Study 2 found that the reciprocity prime manipulation led to higher intentions to donate than in controls, particularly in online mode, but there was no overall effect on behaviour. Taken together, these findings suggest that reciprocity priming may be effective in increasing organ donor registration intentions, but this increase in intention may not translate into donation behaviour.

It has previously been claimed that the modality of communication in itself makes little difference to the effectiveness of organ donation campaigns, although interactions may occur between modality of messages and individuals' characteristics (Falomir-Pichastor, Berent \& Pereira, 2013). It was striking in Study 2 that in face-to-face mode, intentions in the control and reciprocity prime conditions were identical. We speculate that the face-to-face mode of delivery may have led to an increase in socially desirable responding in control participants, i.e. direct interaction with the research assistant may have led to a demand characteristic that elevated intention scores, thus representing a possible question-behaviour (Rodrigues \& Sniehotta, 2015) or form of delivery effect (Dombrowski, O’Carroll \& Williams, 2016). This may have masked a genuine priming effect on behaviour.

\section{Strengths and limitations}


Taken together, the current studies provide evidence that priming people to consider their own acceptance of donated organs using both face-to-face and online methods may increase their intentions to sign the organ donor register. This supports the use of the current UK NHS Blood and Transplants marketing materials. To our knowledge, the current study also represents the first investigation of the comparison between face-to-face and online message delivery regarding organ donation intentions.

However, some limitations should be noted. First, reported intention to register as an organ donor may not translate into action, and our proxy behavioural measure of organ donor registration is somewhat limited in that seeking information about registration may not necessarily lead to actual registration. Exploration of the extent to which reported registration intention relates to actual registration, and of ways in which reciprocity priming can be used to increase objectively measured donor registration behaviour, would be beneficial.

Second, in Study 2, organ donor registration behaviour was seemingly unaffected by the reciprocity prime. We speculate that the demand characteristics of the face-to-face interaction in Study 2 may have increased socially desirable responding in controls and this question-behaviour/form of delivery effect may have masked our ability to detect any reciprocity priming effects on behaviour. Future research should seek to reduce these kinds of biases and find more reliable ways of measuring behaviour.

Finally, the measures employed provided no opportunity for people who were currently not registered organ donors due to being unable to donate, to report this. We suspect that this would be a small number of people as there is no age limit on becoming an organ and/or tissue donor and few medical conditions prevent someone form from donating their organs (NHSBT, 2017). The impact of reciprocity priming on reported intentions to donate (where one is able to do so) may have been underestimated. Measures employed in future research should enable identification of participants who are unable to donate (even if they 
wanted to), so that effects on intention can be more reliably determined within just those participants who are actually able to donate.

\section{Conclusions}

Encouraging participants to consider whether they would accept a donated organ themselves may be effective in increasing organ donor registration intentions. However, it is unclear whether this increase in intentions will translate into organ donation behaviour. Future intervention studies should employ verified organ donor registration as a primary outcome (e.g. O'Carroll, Shepherd, Hayes \& Ferguson, 2016) and seek to reduce bias brought about by socially desirable responding. 


\section{References}

Behavioural Insights Team (2013). Applying Behavioural Insights to Organ Donation: Preliminary Results from a Randomised Controlled Trial. London, UK: Cabinet Office Behavioural Insights Team.

Bolt, S., Venbrux, E., Eisinga, R., Kuks, J.B.M., Veening, J.G., \& Gerrits, P.O. (2010). Motivation for body donation to science: More than an altruistic act. Annals of Anatomy, 192(2), 70-74. DOI: 10.1016/j.aanat.2010.02.002.

Casler, K., Bickel, L. \& Hackett, E. (2013). Separate but equal? A comparison of participants and data gathered via Amazon's MTurk, social media, and face-to-face behavioural testing. Computers in Human Behaviour, 29(6), 2156-2160. DOI: 10.1016/j.chb.2013.05.009.

Cornwall, J., Perry, G.F., Louw, G., \& Stringer, M.D. (2012). Who donates their body to science? An international, multicentre, prospective study. Anatomical Sciences Education, 5(4), 208-216. DOI: 10.1002/ase.1278.

Delaney, M. F., \& White, K. M. (2015). Predicting People's Intention to Donate Their Body to Medical Science and Research. The Journal of social psychology, 155(3), 221-237. DOI: $10.1080 / 00224545.2014 .998962$.

Department of Health (2000). The Review of the United Kingdom Transplant Support Service Authority (UKTSSA) 1998/99. London, UK: Department of Health.

Dombrowksi, S., O’Carroll, R.E. \& Williams, B. (2016). Form of delivery as a key “active ingredient" in behaviour change interventions. British Journal of Health Psychology, 21, 733-740. DOI: 10.1111/bjhp.12203.

Elster, J. (1990). Selfishness and altruism. In J.J. Mansbridge (Ed.) Beyond Self-Interest. Chicago, US: University of Chicago Press. 
Falomir-Pichastor, J. M., Berent, J. A., \& Pereira, A. (2013). Social psychological factors of post-mortem organ donation: a theoretical review of determinants and promotion strategies. Health Psychology Review, 7(2), 202-247. DOI: 10.1080/17437199.2011.570516.

Landry, D.W. (2006). Voluntary reciprocal altruism: A novel strategy to encourage deceased organ donation. Kidney international, 69(6), 957-959. DOI: 10.1038/sj.ki.5000280.

Nadel, M.S., \& Nadel, C.A. (2005). Using reciprocity to motivate organ donations. Yale Journal of Health, Policy, Law, and Ethics, 5, 293-325.

Nagel, T. (1970). The Possibility of Altruism. Oxford, UK: Clarendon Press.

NHS Blood and Transplant (2013). NHSBT Organ Donation: 2013 research [online]. Available at: http://www.nhsbt.nhs.uk/to2020/the-strategy/supporting-documents/nhsbtorgan-donor-report-140813.pdf [accessed 29th Nov 2016].

NHS Blood and Transplant (2016a). Organ Donation and Transplantation Annual Activity Report 2015-2016 [online]. Available from: http://www.odt.nhs.uk/pdf/activityreport/activity_report_2015_16.pdf [accessed 27 $7^{\text {th }}$ Jan 2017].

NHS Blood and Transplant (2016b). Organ donation [online]. Available from: https://www.organdonation.nhs.uk/ [accessed 30 ${ }^{\text {th }}$ Nov 2016].

NHS Blood and Transplant (2017). Eligibility [online]. Available from: https://www.organdonation.nhs.uk/faq/eligibility/ [accessed $21^{\text {st }}$ Apr 2017].

Nichols, A.L. \& Maner, J.K. (2008). The Good-Subject Effect: Investigating participant demand characteristics. Journal of General Psychology, 135(2), 151-166. DOI: 10.3200/GENP.135.2.151-166.

Nuffield Council on Bioethics (2011). Human bodies: donation for medicine and research. London, UK: Nuffield Council on Bioethics. 
O’Carroll, R.E., Shepherd. L., Hayes, P.C. \& Ferguson, E. (2016). Anticipated regret and organ donor registration: A randomised controlled trail. Health Psychology, 35(11), 11691177. DOI: $10.1037 /$ hea0000363.

Rodrigues, A.M. \& Sniehotta, F.F. (2015). The question-behaviour effect: Genuine effect or spurious phenomenon? A systematic review of randomized controlled trials with metaanalyses. Health Psychology, 34(1), 61-78. DOI: 10.1037/hea0000104.

Saunders, B. (2012). Altruism or solidarity? The motives for organ donation and two proposals. Bioethics, 26(7), 376-381. DOI: 10.1111/j.1467-8519.2012.01989.x.

Schwartz, S.H. (1977). Normative influences on altruism. Advances in Experimental Social Psychology, 10, 221-279. DOI: 10.1016/S0065-2601(08)60358-5.

Silk, J.B. (2013). Reciprocal altruism. Current Biology, 23(18), R827-R828. DOI: 10.1016/j.cub.2013.03.052.

Stijnen, M.M., \& Dijker, A.J. (2010). Reciprocity and need in posthumous organ donation: The mediating role of moral emotions. Social Psychological and Personality Science, 2(4), 387-394. DOI: 10.1177/1948550610393749.

Trivers, R.L. (1971). The evolution of reciprocal altruism. Quarterly Review of Biology, 46(1), 35-57. DOI: 10.1086/406755.

Wiborg, J.F., Knoop, H., Wensing, M. \& Bleijenberg, G. (2012). Therapist effects and the dissemination of cognitive behaviour therapy for chronic fatigue syndrome in communitybased mental health care. Behavioural Research \& Therapy, 50(6), 393-396. DOI: 10.1016/j.brat.2012.03.002.

Wing, R.R., Tate, D.F., Gorin, A.A. \& Raynor, H.A. (2006). A self-regulation program for maintenance of weight loss. New England Journal of Medicine, 355, 1563-1571. DOI: 10.1056/NEJMoa061883. 
Table 1: Participant demographics (Study 1).

\begin{tabular}{|c|c|c|c|c|c|c|}
\hline & $\begin{array}{c}\text { Full } \\
\text { sample }\end{array}$ & $\begin{array}{l}\text { Non- } \\
\text { donors }\end{array}$ & Prime & Control & $\begin{array}{c}\text { Face-to- } \\
\text { face }\end{array}$ & Online \\
\hline $\mathrm{N}$ & 244 & 140 & 71 & 69 & 83 & 57 \\
\hline Female $\%(\mathrm{~N})$ & $59.4(145)$ & $57.1(80)$ & $52.1(37)$ & $62.3(43)$ & $56.6(47)$ & $57.9(33)$ \\
\hline Age $18-24$ & $32.0(78)$ & $35.0(49)$ & 40.8 (29) & $29.0(20)$ & $37.3(31)$ & $31.6(18)$ \\
\hline$\% \quad 25-34$ & $27.9(68)$ & $26.4(37)$ & 25.4 (18) & 27.5 (19) & $26.5(22)$ & $26.3(15)$ \\
\hline (N) $\quad 35-44$ & $17.2(42)$ & $17.9(25)$ & 16.9 (12) & $18.8(13)$ & $10.8(9)$ & $28.1(16)$ \\
\hline $45-54$ & $13.5(33)$ & $10.7(15)$ & $7.0(5)$ & $14.5(10)$ & $13.3(11)$ & $7.0(4)$ \\
\hline $55-64$ & $8.2(20)$ & $7.9(11)$ & $8.5(6)$ & $7.2(5)$ & $8.4(7)$ & $7.0(4)$ \\
\hline $65+$ & $1.2(3)$ & $2.1(3)$ & $1.4(1)$ & $2.9(2)$ & $3.6(3)$ & 0 \\
\hline
\end{tabular}


Table 2: Summary of participants in each condition, through each mode of delivery (Study 1).

\begin{tabular}{|l|r|r|r|}
\hline \multicolumn{1}{|c|}{ Mode of delivery } & \multicolumn{1}{c|}{ Prime } & \multicolumn{1}{c|}{ Control } & \multicolumn{1}{c|}{ Total } \\
& $\%(\mathrm{~N})$ & \multicolumn{1}{c|}{$\%(\mathrm{~N})$} & $\%(\mathrm{~N})$ \\
\hline Face-to-face & $33.6(47)$ & $25.7(36)$ & $59.3(83)$ \\
\hline Online & $17.1(24)$ & $23.6(33)$ & $40.7(57)$ \\
\hline Total & $50.7(71)$ & $49.3(69)$ & 140 \\
\hline
\end{tabular}


Table 3: Means and standard deviations for organ donation intentions (Study 1).

\begin{tabular}{|l|r|r|r|}
\hline & $\begin{array}{c}\text { Reciprocity prime } \\
\text { Mean (SD) }\end{array}$ & $\begin{array}{c}\text { Control group } \\
\text { Mean (SD) }\end{array}$ & $\begin{array}{r}\text { All participants } \\
\text { Mean (SD) }\end{array}$ \\
\hline Face-to-face $(\mathrm{N}=83)$ & $5.54(1.20)$ & $4.85(1.49)$ & $5.24(1.37)$ \\
\hline Online $(\mathrm{N}=57)$ & $5.83(1.05)$ & $5.08(1.40)$ & $5.39(1.31)$ \\
\hline All $(\mathrm{N}=140)$ & $5.64(1.15)$ & $4.96(1.44)$ & $5.30(1.34)$ \\
\hline
\end{tabular}


Table 4: Participant demographics (Study 2).

\begin{tabular}{|c|c|c|c|c|c|c|}
\hline & $\begin{array}{c}\text { Full } \\
\text { sample }\end{array}$ & $\begin{array}{l}\text { Non- } \\
\text { donors }\end{array}$ & Prime & Control & $\begin{array}{c}\text { Face-to- } \\
\text { face }\end{array}$ & Online \\
\hline $\mathrm{N}$ & 1,066 & 518 & 244 & 274 & 336 & 182 \\
\hline Female $\%(\mathrm{~N})$ & $55.2(588)$ & $49.7(257)$ & $51.4(125)$ & $48.2(132)$ & 43.9 (147) & $60.4(110)$ \\
\hline Age $18-24$ & $16.2(172)$ & $15.5(80)$ & $14.4(35)$ & $16.4(45)$ & $14.0(47)$ & $18.1(33)$ \\
\hline$\% \quad 25-34$ & $12.8(136)$ & $11.6(60)$ & $11.9(29)$ & $11.3(31)$ & $11.3(38)$ & $12.2(22)$ \\
\hline (N) $\quad 35-44$ & $14.6(155)$ & $12.2(63)$ & $12.8(31)$ & $11.7(32)$ & $12.8(43)$ & $11.0(20)$ \\
\hline $45-54$ & $26.0(277)$ & $22.6(117)$ & $27.6(67)$ & $18.2(50)$ & $19.9(67)$ & $27.6(50)$ \\
\hline $55-64$ & $15.3(163)$ & $17.4(90)$ & $16.0(39)$ & $18.6(51)$ & $12.5(42)$ & $26.5(48)$ \\
\hline $65+$ & $15.1(161)$ & 20.7 (107) & $17.3(42)$ & $23.7(65)$ & $29.5(99)$ & $4.4(8)$ \\
\hline
\end{tabular}


Table 5: Summary of participants in each condition, in each part of the study (Study 2).

\begin{tabular}{|l|r|r|r|}
\hline \multicolumn{1}{|c|}{ Mode of delivery } & \multicolumn{1}{c|}{ Prime } & \multicolumn{1}{c|}{ Control } & \multicolumn{1}{c|}{ Total } \\
& $\%(\mathrm{~N})$ & \multicolumn{1}{c|}{$\%(\mathrm{~N})$} & $\%(\mathrm{~N})$ \\
\hline Face-to-face & $29.3(152)$ & $35.5(184)$ & $64.9(336)$ \\
\hline Online & $17.8(92)$ & $17.4(90)$ & $35.1(182)$ \\
\hline Total & $47.1(244)$ & $52.9(274)$ & 518 \\
\hline
\end{tabular}


Table 6: Means and standard deviations for organ donation intentions (Study 2).

\begin{tabular}{|l|r|r|r|}
\hline & \multicolumn{1}{|c|}{$\begin{array}{c}\text { Prime } \\
\text { Mean (SD) }\end{array}$} & \multicolumn{1}{c|}{$\begin{array}{c}\text { Control } \\
\text { Mean (SD) }\end{array}$} & \multicolumn{1}{c|}{ Mean (SD) } \\
\hline Face-to-face $(\mathrm{N}=331)$ & $4.90(2.01)$ & $4.90(1.93)$ & $4.90(1.96)$ \\
\hline Online $(\mathrm{N}=180)$ & $4.99(1.90)$ & $4.16(1.82)$ & $4.58(1.90)$ \\
\hline All $(\mathrm{N}=511)$ & $4.94(1.96)$ & $4.66(1.92)$ & $4.79(1.94)$ \\
\hline
\end{tabular}


Table 7: Numbers and percentages for participants engaging in proxy behavioural measure of organ donor registration (Study 2).

\begin{tabular}{|l|c|c|c|}
\hline & Prime & Control & Total \\
& $\%(\mathrm{~N})$ & $\%(\mathrm{~N})$ & $\%(\mathrm{~N})$ \\
\hline Took leaflet $(\mathrm{N}=333)$ & $56.3(85)$ & $68.7(125)$ & $63.1(210)$ \\
\hline Face-to-face) & & & \\
\hline (Online) & $36.4(32)$ & $23.9(21)$ & $30.1(53)$ \\
\hline Total $(\mathrm{N}=509)$ & $49.0(117)$ & $54.1(146)$ & $51.7(263)$ \\
& & & \\
\hline
\end{tabular}


If you needed an organ transplant would you have one? - Reciprocity priming and organ donation

Objective: There are approximately 6,500 people on the UK national transplant waiting list, and around 400 of these die every year. Only $35 \%$ of the UK population are currently on the organ donation register. We report 2 studies examining whether a reciprocity prime, in which participants were asked whether they would accept a donated organ, increased organ donation intentions and behaviour. Design: Between participants, randomized-controlled design Methods: In 2 studies, participants who were not currently registered organ donors took part in a face-to-face setting or online, and were randomly allocated to a reciprocity prime or control condition. Following the manipulation they were asked to indicated their intention to join the organ donor register. In Study 2, participants were then offered an organ donation information leaflet or the opportunity to click a link for further information (proxy behavioural measure). Results: In both studies, reciprocity primed participants reported greater intentions to register than controls. However, in Study 2, no effect on donation behaviour was found. Conclusions: Reciprocal altruism may be a useful tool in increasing intentions to join the organ donor register. Further evaluation is required to determine whether this increase in intention can be translated into organ donation behaviour. 
Around 6,500 people in the UK are in need of an organ transplant at any given time, but with only $35 \%$ of the UK population registered to donate their organs, many people die each year whilst waiting for an organ (NHSBT, 2016a). This is despite the UK population holding generally positive views about organ donation, with $86 \%$ of individuals supporting it, and 51\% strongly supporting it (NHSBT, 2013). The development of effective strategies to translate these positive views into action is imperative to increasing the number of registered donors and saving lives.

\section{Reciprocal altruism}

Trivers (1971) described altruism as "behaviour that benefits another organism... while being apparently detrimental to the organism performing the behaviour, benefit and detriment being defined in terms of contribution to inclusive fitness" (p35). Reciprocal altruism (RA) has been described as "a process that favours costly cooperation among reciprocating partners" (Silk, 2013; p827), and has been observed across a number of species (Silk, 2013; Trivers, 1971). RA is vital for group cohesion and for ensuring survival of the group, and has thereby played an important role in human evolution. RA elicits a sense of joint moral obligation, in which each party is expected to make their own relative contribution for the advancement of the group, and deviation from expected norms results in disapproval, guilt or even punishment.

Traditionally, one-way altruism has been considered intrinsic to both blood and organ donation, in that the actions of the donor are intended to benefit the recipient without necessary reward or benefit to themselves (Nuffield Council on Bioethics, 2011; Department of Health, 2000; Elster, 1990). The altruistic desires to aid medical science and to be useful after death have been cited as the most common reasons for organ donor registration (Bolt, Venbrux, Eisinga, Kuks, Veening \& Gerrits, 2010; Cornwall, Perry, Louw \& Stringer, 2012) and perceived moral norms appear to play a significant role in organ donation decisions 
(Delaney \& White, 2015). However, given the low rates of registration to become an organ donor, altruism alone is clearly not sufficient to ensure that supply meets demand. RA has been proposed as a potentially effective strategy through which organ donor registration might be increased.

Landry (2006) argued that altruism can be reinforced by reciprocity, and that in a system where altruists are reciprocally rewarded for their altruism - whilst those who violate altruistic norms are disadvantaged - altruism will thrive. He argued that in order to overcome the many barriers that prevent people from registering as organ donors, campaigns must appeal to individuals' self-interest, which must be balanced with their desire to do what is fair and just. For example, he suggested that the choice between donating one's organs (altruism) and not donating one's organs (selfishness) should include an additional third option, in which one can opt to donate one's organs to only those who have also agreed to donate theirs (reciprocal altruism). This third option suggests to the decision-maker that there is a potential penalty for not behaving altruistically, such that should they choose not to donate their organs and later require an organ themselves, they would not receive one from those who engage only in reciprocal altruism. He tested these ideas in a pilot study with medical students. At baseline, $59 \%$ were willing to donate their organs. When questioned about their willingness to accept an organ if they needed it to save their life, 100\% stated that they would. When this was then followed up with a question about their willingness to donate their organs, $74 \%$ now said they would, $20 \%$ said they would but only reciprocally, and only $2 \%$ refused. Prompting participants to consider their own potential future need for an organ, along with the suggestion that they might be disadvantaged if they refused to donate their own, substantially increased donation intentions. Landry argues that employing reciprocal altruism in this way could be an effective method through which organ donations might be increased. Nadel and Nadel (2005) agree with this view and further suggest that much like time spent on an organ 
waiting list contributes to who receives an organ, so too should time spent on a donor list, such that registering early on in life carries extra benefits.

The NHS Blood and Transplant campaign currently attempts to draw upon reciprocal altruism, asking "If you needed an organ transplant would you have one?" in its marketing materials (NHSBT, 2016b). The Cabinet Office's Behavioural Insights Team (in collaboration with NHS Blood and Transplant, the Government Digital Service, the Department of Health, and the Driving and Vehicle Licencing Agency) found that displaying these types of messages (specifically, "If you needed an organ transplant, would you have one? If so, please help others") on high traffic www.GOV.UK webpages encouraged people to register as organ donors. They estimate that an extra 96,000 registrations could be achieved per year using this type of reciprocity priming (BIT, 2013). It could be argued that prompting participants to adopt the perspective of the recipient may promote ideas of self-preservation, and increase levels of empathy towards those in need of organs. Additionally, the decision to donate one's organs may also be affected by consideration of potential recipients' donor registration status (which of course would be unlikely to affect outcomes for the original donor). Stijnen and Dijker (2010) found that participants perceived organ donation to be more just when potential recipients were themselves registered donors. Recipients who were not registered donors themselves aroused feelings of injustice and anger, and donation to such recipients elicited less sympathy and less positive self-feelings than did donation to registered donor recipients. Contribution to a "common pool" of organs from which other contributors may benefit (at the exclusion of non-donors), may therefore be perceived by many as the fairest system.

\section{The current research}

This paper reports on two studies. Study 1 had two aims: i) to determine whether a reciprocity prime is effective in increasing organ donor registration intentions in those who are not currently registered; and ii) to determine whether any differences observed depend on 
the mode through which the study is conducted (face-to-face versus online). Study 2 had three aims: i) to determine whether a reciprocity prime is effective in increasing organ donor registration intentions; ii) to determine whether a reciprocity prime has any effect on a proxy behavioural measure of organ donor registration, i.e. taking an information leaflet or viewing a registration site; and iii) to examine whether the mode through which the study is conducted (face-to-face or online) makes any difference to stated organ donor registration intentions.

\section{Study 1: Methods}

\section{Participants}

244 participants over the age of 18 were recruited, of whom $57.4 \%(\mathrm{~N}=140)$ were not currently registered organ donors. Of these, 83 took part in the face-to-face part of the study, and 57 in the online part. Demographic information for participants can be found in Table 1, whilst Table 2 illustrates the breakdown of participants in each condition, for each mode of delivery. Those who were unsure whether or not they were registered organ donors were excluded from the study.

[Table 1 about here]

[Table 2 about here]

\section{Design}

A between participants, randomized-controlled design was used. Those not currently registered as organ donors were randomly assigned to either the reciprocity prime condition or a control condition to determine the effect of a reciprocity prime on reported intention to 
register as an organ donor. The same applied to both the face-to-face and online components of the study.

\section{Procedure}

For the face-to-face delivery mode, participants were recruited opportunistically, through approaching potential participants around the university campus and local workplaces. For online delivery, participants were recruited opportunistically through advertisements on social media. All participants received an information sheet and were invited to sign a consent form/click a consent box. Consenting participants provided basic demographics. Those not currently registered as organ donors were randomly allocated (using an online randomiser $-\underline{w w w . r a n d o m i z e r . o r g}$ ) to either the reciprocity prime or control condition. Prime condition participants completed a short questionnaire consisting of a priming question and two questions regarding intention to register as an organ donor (see "Measures" below). Control condition participants completed a similar questionnaire with a neutral "filler" question in place of the prime, and the same two questions regarding intention to register as an organ donor. Ethical approval for the study was obtained from the University of XXX Psychology Ethics Committee.

\section{Measures}

Reciprocity prime/ control. The reciprocity prime was based on marketing materials used by the UK NHS Blood and Transplant's organ donation campaign. Participants were required to respond on a seven-point likert scale from "Strongly disagree" to "Strongly agree", to the item "I would accept an organ from a deceased donor in order to save my own life". The control item was "Organ donation is important", and participants responded on the same seven-point scale.

Organ donation registration intention. All participants responded to the same two intention items: "I strongly intend to donate my organs in the future" and "I will definitely 
donate my organs when I die". Responses to both items were given on the same seven-point scale as above, and averaged to produce one overall organ donation registration intention score.

Other measures. All participants (both registered donors and non-donors) also completed an affective attitudes scale in relation to organ donation (Morgan, Stephenson, Harrison, Afifi, \& Long, 2008; O’Carroll, Foster, McGeechan, Sandford \& Ferguson, 2011) and donors, as expected, scored significantly lower on bodily integrity and "ick" factor and higher on perceived benefits. The results are not reported here but are available upon request. Analyses

Chi-squared analyses were used to determine whether there were any differences in demographic characteristics between prime condition participants and control participants. A two-way mixed ANOVA was run to compare differences in intention to donate, across experimental conditions and modes of delivery.

\section{Study 1: Results}

\section{Demographic characteristic comparisons}

No significant differences were found in age $\left(\chi^{2}(5)=3.78, p=.581\right)$ or gender $\left(\chi^{2}(1)\right.$ $=1.49, \mathrm{p}=.222$ ) between prime and control participants.

\section{Effect of reciprocity prime and mode of delivery on registration intentions}

The means and standard deviations for intention to donate organs in each condition are illustrated in Table 3.

[Table 3 about here] 
A two-way mixed ANOVA was run to test for differences in intention to donate organs between those in the reciprocity prime condition and controls, and to test for any interaction between experimental condition and mode of delivery. A main effect was found for experimental group, with prime condition participants scoring significantly higher on intention than controls $\left(\mathrm{F}(1,136)=10.24, \mathrm{p}=.002\right.$, partial $\left.\mathrm{y}^{2}=.07\right)$, but no significant effect was found for mode of delivery $(\mathrm{F}(1,136)=1.31, \mathrm{p}=.255)$, and no interaction effect was observed $(\mathrm{F}(1,136)=.02, \mathrm{p}=.891)$.

\section{Study 2: Methods}

\section{Participants}

1,065 participants over the age of 18 were recruited in total, $48.5 \%$ of whom reported that they were not currently registered organ donors. For the face-to-face component of the study, 599 participants (336 non-donors) were recruited opportunistically from several Scottish town/city centres (Glasgow, Edinburgh, Stirling, Aberdeen and Perth). For the online component, 466 participants (181 non-donors) were recruited online via social media, email, the University online portal, and several local workplaces (a financial company, a hotel company, a computer technologies company, a further education college and a befriending charity). Participant demographics are illustrated in Table 4. Those who were unsure whether or not they were registered organ donors were treated as though they were not registered (i.e. they were allocated to either the prime or control condition). Table 5 illustrates a breakdown of participants in each condition, for each part of the study.

[Table 4 about here]

[Table5 about here] 


\section{Design}

A similar between participants, randomized-controlled design was used, across two separate modes of delivery. In both modes, those not currently registered as organ donors were randomly assigned to either the reciprocity prime or control condition to determine the effect of a reciprocity prime on reported intention to register as an organ donor, and on the likelihood of either taking an organ donor information leaflet (face-to-face mode) or clicking on a link to the NHS organ donor registration site (online mode) (both proxy behavioural measures of organ donor registration).

\section{Procedure}

All participants were given information on the study and were invited to sign a consent form/tick a consent box. Consenting participants provided basic demographics, and those not currently registered as organ donors were randomly allocated (using www.randomizer.org/) to either the reciprocity prime or control condition. Across both modes of delivery, prime condition participants completed a short questionnaire consisting of a priming question and two questions regarding intention to register as an organ donor (see "Measures" below). Control condition participants completed only the two questions regarding intention to register as an organ donor (see below). Ethical approval for the study was obtained from the University of XXX Psychology Ethics Committee.

\section{Measures}

Reciprocity prime. For both modes of delivery, those in the reciprocity prime condition were required to respond to the item "I would accept an organ from a deceased donor in order to save my own life", on a seven-point likert scale from "Strongly disagree" to "Strongly agree". 
Organ donation registration intention. Both reciprocity prime and control participants were then required to respond to the same two intention items: "I strongly intend to donate my organs when I die" and "I will definitely donate my organs when I die", on the same seven-point scale as above. Scores were averaged to produce one overall organ donation registration intention score.

Behavioural measure of organ donor registration. Following questionnaire completion, participants in the face-to-face component were offered a leaflet on organ donation. Whether or not they took one was recorded. Participants of the online component were asked "Would you like to see the link to the NHS website to register as an organ donor?". Whether they clicked "yes" or "no" was recorded.

Other measures. In the face-to-face component, all recruited participants (both donors and non-donors) also completed an altruism scale (Rushton, Chrisjohn \& Fekken, 1981) and donors, as expected, scored significantly higher than non-donors. In the online component, all recruited participants also completed a health locus of control scale (Wallston, Wallston \& DeVellis, 1978) and donors, as expected, scored significantly higher on internal locus of control. Further details are available on request.

\section{Analyses}

Chi-squared tests examined differences in demographic characteristics between prime condition participants and controls. A two-way mixed ANOVA was used to compare mean organ donation registration intentions between participants in the prime condition and in the control condition, and between face-to-face and online delivery. Chi-squared tests were used to determine whether there was a difference in taking an information leaflet (face-to-face), or in opting to see the link to the NHS organ donation registration website (online), between those in the prime condition and controls. 


\section{Study 2: Results}

\section{Demographic characteristic comparisons}

Prime condition participants did not differ significantly from controls in age $\left(\chi^{2}(5)=\right.$ $8.13, \mathrm{p}=.149)$ or gender $\left(\chi^{2}(1)=0.62, \mathrm{p}=.430\right)$.

\section{Effect of reciprocity prime on registration intentions}

The means and standard deviations for intention to donate organs in each condition are illustrated in Table 6.

\section{[Table 6 about here]}

A two-way mixed ANOVA found a significant main effect of experimental group on intention: those in the reciprocity prime group had higher intention scores than controls (F (1, $507)=5.39, \mathrm{p}=.021$, partial $\left.\mathrm{y}^{2}=.01\right)$. No main effect on intention was found for mode of delivery $(\mathrm{F}(1,507)=3.34, \mathrm{p}=.068)$, but a significant interaction was found between experimental group and mode of delivery, $\left(\mathrm{F}(1,507)=5.32, \mathrm{p}=.021\right.$, partial $\left.\eta^{2}=.01\right)$, with those in the prime group scoring higher on intention than controls when the prime was delivered online compared to face-to-face.

Examination of individual means indicated that in the face-to-face delivery format, the scores for intention were identical in the prime and control conditions (4.90) but there appeared to be a difference between intention scores in the face-to-face control group and the online control group. A post-hoc independent samples t-test confirmed that intention scores were significantly higher in the face-to-face control group than in the online control group ( $\mathrm{t}$ $(269)=3.03, \mathrm{p}=.003)$, whilst no such differences existed between the face-to-face prime group and the online prime group $(\mathrm{t}(238)=0.33, \mathrm{p}=.745)$.

\section{Effect of reciprocity prime on leaflet collection/web-link viewing}


Overall, there was no difference in taking a leaflet/clicking the link between prime and control participants, with $49.0 \%$ of prime condition participants doing so, and $54.1 \%$ of controls $\left(\chi^{2}(1)=1.33, p=.249\right)$. When broken down by delivery mode, controls in face-toface mode were more likely to take an information leaflet (68.7\%) than those in the prime condition $(56.3 \%)\left(\chi^{2}(1)=5.44, p=.020\right)$, but in online mode, there was no difference in clicking on the organ donation link between prime (36.4\%) and control (23.9\%) participants $\left(\chi^{2}(1)=3.27, \mathrm{p}=.071\right)$

\section{Overall Discussion}

In Study 1 a reciprocity prime manipulation led to greater reported intentions to sign the organ donor register, regardless of whether this was done face-to-face or online.

Similarly, Study 2 found that the reciprocity prime manipulation led to higher intentions to donate than in controls, particularly in online mode, but there was no overall effect on behaviour. Taken together, these findings suggest that reciprocity priming may be effective in increasing organ donor registration intentions, but this increase in intention may not translate into donation behaviour.

It has previously been found that the modality of communication in itself makes little difference to the effectiveness of organ donation campaigns, although interactions may occur between modality of messages and individuals' characteristics (Falomir-Pichastor, Berent \& Pereira, 2013). It was striking in Study 2 that in face-to-face mode, intentions in the control and reciprocity prime conditions were identical. We speculate that the face-to-face mode of delivery may have led to an increase in socially desirable responding in control participants, i.e. direct interaction with the research assistant may have led to a demand characteristic that elevated intention scores, thus representing a possible question-behaviour effect (Rodrigues \& Sniehotta, 2015). This may have masked a genuine priming effect on behaviour. 


\section{Strengths and limitations}

Taken together, the current studies provide evidence that priming people to consider their own acceptance of donated organs using both face-to-face and online methods may increase their intentions to sign the organ donor register. This supports the use of the current NHS Blood and Transplants marketing materials. To our knowledge, the current study also represents the first investigation of the comparison between face-to-face and online message delivery regarding organ donation intentions.

However, in Study 2 organ donor registration behaviour was seemingly unaffected by the reciprocity prime. We speculate that the demand characteristics of the face-to-face interaction in Study 2 may have increased socially desirable responding in controls and this question-behaviour effect may have masked our ability to detect any reciprocity priming effects on behaviour.

\section{Conclusions}

Encouraging participants to consider whether they would accept a donated organ themselves may be effective in increasing organ donor registration decisions. However, it is unclear whether this increase in intentions will translate into organ donation behaviour. Future intervention studies should employ verified organ donor registration as a primary outcome (e.g. O’Carroll, Shepherd, Hayes \& Ferguson, 2016). 


\section{References}

Behavioural Insights Team (2013). Applying Behavioural Insights to Organ Donation: Preliminary Results from a Randomised Controlled Trial. London, UK: Cabinet Office Behavioural Insights Team.

Bolt, S., Venbrux, E., Eisinga, R., Kuks, J.B.M., Veening, J.G., \& Gerrits, P.O. (2010). Motivation for body donation to science: More than an altruistic act. Annals of Anatomy, 192(2), 70-74. DOI: 10.1016/j.aanat.2010.02.002.

Cornwall, J., Perry, G.F., Louw, G., \& Stringer, M.D. (2012). Who donates their body to science? An international, multicentre, prospective study. Anatomical Sciences Education, 5(4), 208-216. DOI: 10.1002/ase.1278.

Delaney, M. F., \& White, K. M. (2015). Predicting People's Intention to Donate Their Body to Medical Science and Research. The Journal of social psychology, 155(3), 221-237. DOI: $10.1080 / 00224545.2014 .998962$.

Elster, J. (1990). Selfishness and altruism. In J.J. Mansbridge (Ed.) Beyond Self-Interest. Chicago, US: University of Chicago Press.

Falomir-Pichastor, J. M., Berent, J. A., \& Pereira, A. (2013). Social psychological factors of post-mortem organ donation: a theoretical review of determinants and promotion strategies. Health Psychology Review, 7(2), 202-247. DOI: 10.1080/17437199.2011.570516.

Landry, D.W. (2006). Voluntary reciprocal altruism: A novel strategy to encourage deceased organ donation. Kidney international, 69(6), 957-959. DOI: 10.1038/sj.ki.5000280.

Morgan, S.E., Stephenson, M.T., Harrison, T.R., Afifi, W A., \& Long, S.D. (2008). Facts versus feelings: How rational is the decision to become an organ donor? Journal of Health Psychology, 13(5), 644-658. DOI: 10.1177/1359105308090936. 
Nadel, M.S., \& Nadel, C.A. (2005). Using reciprocity to motivate organ donations. Yale Journal of Health, Policy, Law, and Ethics, 5, 293-325.

NHS Blood and Transplant (2013). NHSBT Organ Donation: 2013 research [online]. Available at: http://www.nhsbt.nhs.uk/to2020/the-strategy/supporting-documents/nhsbtorgan-donor-report-140813.pdf [accessed 29th Nov 2016].

NHS Blood and Transplant (2016a). Organ Donation and Transplantation Annual Activity Report 2015-2016 [online]. Available from: http://www.odt.nhs.uk/pdf/activityreport/activity_report_2015_16.pdf[accessed 27 $7^{\text {th }}$ Jan 2017].

NHS Blood and Transplant (2016b). Organ donation [online]. Available from: https://www.organdonation.nhs.uk/ [accessed $30^{\text {th }}$ Nov 2016].

Nuffield Council on Bioethics (2011). Human bodies: donation for medicine and research. London, UK: Nuffield Council on Bioethics.

O'Carroll, R.E., Foster, C., McGeechan, G., Sandford, K., \& Ferguson, E. (2011). The “ick" factor, anticipated regret, and willingness to become an organ donor. Health Psychology, 30(2), 236-245. DOI: 10.1037/a0022379.

O’Carroll, R.E., Shepherd. L., Hayes, P.C. \& Ferguson, E. (2016). Anticipated regret and organ donor registration: A randomised controlled trail. Health Psychology, 35(11), 11691177. DOI: $10.1037 /$ hea0000363.

Organ Donation Scotland (2016). Tell me more [online]. Available from: https://www.organdonationscotland.org/tell-me-more [accessed 29th Nov 2016].

Rodrigues, A.M. \& Sniehotta, F.F. (2015). The question-behaviour effect: Genuine effect or spurious phenomenon? A systematic review of randomized controlled trials with metaanalyses. Health Psychology, 34(1), 61-78. 
Rushton, J.P., Chrisjohn, R.D., \& Fekken, G.C. (1981). The altruistic personality and the selfreport altruism scale. Personality and Individual Differences, 2, 293-302. DOI: 10.1016/0191-8869(81)90084-2.

Silk, J.B. (2013). Reciprocal altruism. Current Biology, 23(18), R827-R828. DOI: 10.1016/j.cub.2013.03.052.

Stijnen, M.M., \& Dijker, A.J. (2010). Reciprocity and need in posthumous organ donation: The mediating role of moral emotions. Social Psychological and Personality Science, 2(4), 387-394. DOI: 10.1177/1948550610393749.

Trivers, R.L. (1971). The evolution of reciprocal altruism. Quarterly Review of Biology, 46(1), 35-57. DOI: 10.1086/406755.

Wallston, K.A., Wallston, B.S., \& DeVellis, R. (1978). Development of the multidimensional health locus of control (MHLC) scales. Health Education Monographs, 6, 160-170. DOI: 10.1177/109019817800600107. 
Table 1: Participant demographics (Study 1).

\begin{tabular}{|c|c|c|c|c|c|c|}
\hline & $\begin{array}{c}\text { Full } \\
\text { sample }\end{array}$ & $\begin{array}{l}\text { Non- } \\
\text { donors }\end{array}$ & Prime & Control & $\begin{array}{c}\text { Face-to- } \\
\text { face }\end{array}$ & Online \\
\hline $\mathrm{N}$ & 244 & 140 & 71 & 69 & 83 & 57 \\
\hline Male \% & 40.6 & 42.9 & 47.9 & 37.7 & 41.9 & 38.2 \\
\hline Age $18-24$ & 32.0 & 35.0 & 40.8 & 29.0 & 33.5 & 29.2 \\
\hline$\% \quad 25-34$ & 27.9 & 26.4 & 25.4 & 27.5 & 29.0 & 25.8 \\
\hline $35-44$ & 17.2 & 17.9 & 16.9 & 18.8 & 15.4 & 20.2 \\
\hline $45-54$ & 13.5 & 10.7 & 7.0 & 14.5 & 12.3 & 15.7 \\
\hline $55-64$ & 8.2 & 7.9 & 8.5 & 7.2 & 7.7 & 9.0 \\
\hline $65+$ & 1.2 & 2.1 & 1.4 & 3.0 & 1.9 & 0 \\
\hline
\end{tabular}


Table 2: Breakdown of participants in each condition, through each mode of delivery (Study 1).

\begin{tabular}{|l|r|r|r|}
\hline \multicolumn{1}{|c|}{ Mode of delivery } & Prime & Control & \multicolumn{2}{|c|}{ Total } \\
\hline Face-to-face & 47 & 36 & 83 \\
\hline Online & 24 & 33 & 57 \\
\hline Total & 71 & 69 & 140 \\
\hline
\end{tabular}


Table 3: Means and standard deviations for organ donation intentions (Study 1).

\begin{tabular}{|l|r|r|r|}
\hline & Reciprocity prime & Control group & \multicolumn{1}{|c|}{ All participants } \\
& Mean (SD) & Mean (SD) & Mean (SD) \\
\hline Face-to-face $(\mathrm{N}=83)$ & $5.54(1.20)$ & $4.85(1.49)$ & $5.24(1.37)$ \\
\hline Online $(\mathrm{N}=57)$ & $5.83(1.05)$ & $5.08(1.40)$ & $5.39(1.31)$ \\
\hline All $(\mathrm{N}=140)$ & $5.64(1.15)$ & & $5.30(1.34)$ \\
\hline
\end{tabular}


Table 4: Participant demographics (Study 2).

\begin{tabular}{|c|c|c|c|c|c|c|}
\hline & $\begin{array}{c}\text { Full } \\
\text { sample }\end{array}$ & $\begin{array}{l}\text { Non- } \\
\text { donors }\end{array}$ & Prime & Control & $\begin{array}{c}\text { Face-to- } \\
\text { face }\end{array}$ & Online \\
\hline $\mathrm{N}$ & 1,065 & 517 & 244 & 273 & 336 & 181 \\
\hline Male \% & 44.8 & 50.3 & 48.1 & 51.8 & 56.1 & 39.2 \\
\hline Age $18-24$ & 16.2 & 15.5 & 14.4 & 16.4 & 14.0 & 18.2 \\
\hline$\% \quad 25-34$ & 12.8 & 11.6 & 12.0 & 11.3 & 11.3 & 12.2 \\
\hline $35-44$ & 14.6 & 12.2 & 12.8 & 11.7 & 12.8 & 11.0 \\
\hline $45-54$ & 26.0 & 22.5 & 27.3 & 18.2 & 19.9 & 27.6 \\
\hline $55-64$ & 15.3 & 17.4 & 16.1 & 18.6 & 12.5 & 26.5 \\
\hline $65+$ & 15.1 & 20.7 & 17.4 & 23.7 & 29.5 & 4.4 \\
\hline
\end{tabular}


Table 5: Breakdown of participants in each condition, in each part of the study (Study 2).

\begin{tabular}{|l|r|r|r|}
\hline \multicolumn{1}{|c|}{ Mode of delivery } & \multicolumn{1}{|c|}{ Prime } & Control & \multicolumn{1}{|c|}{ Total } \\
\hline Face-to-face & 152 & 184 & 336 \\
\hline Online & 91 & 90 & 181 \\
& & & 517 \\
\hline Total & 243 & 274 & \\
& & & \\
\hline
\end{tabular}


Table 6: Means and standard deviations for organ donation intentions (Study 2).

\begin{tabular}{|l|r|r|r|}
\hline & \multicolumn{1}{|c|}{ Prime } & \multicolumn{1}{c|}{ Control } & \multicolumn{1}{c|}{ All } \\
& Mean (SD) & Mean (SD) & Mean (SD) \\
\hline Face-to-face $(\mathrm{N}=331)$ & $4.90(2.01)$ & $4.90(1.93)$ & $4.90(1.96)$ \\
\hline Online $(\mathrm{N}=180)$ & $4.99(1.90)$ & $4.16(1.82)$ & $4.58(1.90)$ \\
\hline All $(\mathrm{N}=511)$ & $4.94(1.96)$ & $4.66(1.92)$ & $4.79(1.94)$ \\
\hline
\end{tabular}

